\title{
LOS LECTORES DE MANUEL GONZÁLEZ PRADA
}

\section{Gema Areta}

\begin{abstract}
"González Prada murió en Lima el 22 de julio de 1918. Con él perdió el Perú el espíritu más puro, el cerebro más vigoroso, la conciencia más honrada, el corazón más abnegado, la voluntad más firme que haya tenido en todos los tiempos."1

"Los hombres de la nueva generación en González Prada admiramos y estimamos, sobre todo, el austero ejemplo moral. Estimamos y admiramos, sobre todo, la honradez intelectual, la noble y fuerte rebeldía.

Pienso, además por mi parte, que González Prada no reconocería en la nueva generación peruana una generación de discípulos y herederos de su obra si no encontrara en sus hombres la voluntad y el aliento indispensable para superarla."2
\end{abstract}

Estas palabras del poeta arequipeño Alberto Hidalgo (1897-1967) y de José Carlos Mariatégui (1894-1930) ofrecen la imagen perfecta que la vanguardia peruana proyectó siempre de quien fue su indiscutible y principal maestro. Si aceptamos esta imagen, estaremos admitiendo también la visión crítica que de la literatura peruana propuso entonces la vanguardia, donde parece levantarse en soledad la ética intelectual de Prada.

Manuel González Prada fue el primer gran rebelde de una literatura cuya dinastía poética mayor, José María Eguren,

César Vallejo, Carlos Germán Belli, Cisneros, César Moro, Martín Adán..., muestra esa constante alienación del mundo contemporáneo. Pero su verbo revolucionario estaba hecho de prosa, es el escritor de los grandes discursos quien nace con la derrota peruana en la Guerra del Pacífico (1879-1884), cuando un fuerte sentimiento patriótico politizó la vida intelectual limeña, puso de moda el estilo apocalíptico y la grandielocuencia, y provocó una importante distorsión estética en la recepción y progresión de los movimientos literarios. Hasta la posguerra la joven escritura de Prada se había dividido entre el teatro y la poesía. Ya por entonces sus versos se convierten en un hacer oculto, "No publicaré nada. Yo debí ser ingeniero, y mi afición me lleva al campo, de las matemáticas, o a la química. Los versos son puro entretenimiento." ${ }^{3}$ Escribe traducciones de Goethe, Schiller, Heine...

\footnotetext{
1 Alberto Hidalgo, Muertos, heridos y contusos, Lima, Imp. Mercatal, 1920, págs. 23-24.

2 José Carlos Mariátegui, 7 Ensayos de interpretación de la realidad peruana, Caracas, Ayacucho, 1979, pág. 172. La primera edición se realizó en 1928.

${ }^{3}$ Cfdo. por Luis Alberto Sánchez, Don Manuel, Lima, Universidad Nacional Mayor de San Marcos, 1964, pág. 53.
} 
imitando estrofas y formas que reunió en un grueso cuaderno titulado "Baladas". Una selección de sus mejores poemas se editan con pseudónimo en El Nacional, donde también aparecen algunos artículos de crítica literaria, y anónimos comentarios violentos sobre la realidad peruana.

En 1868 su interés por un Perú más profundo lo llevó a realizar un largo viaje a caballo por algunas provincias de la región andina, conociendo de cerca la situación de los mineros de Cerro de Pasco y la explotación de la raza indígena. El regreso a Lima lo es también al compromiso formal de una poesía en constante renovación expresiva que se sirve del triolet, el rondel y el pantum como principales formas métricas inéditas, además de romances, sonetos y letrillas.

Sin embargo algo había cambiado, quizás el prestigio alcanzado como escritor empezaba a molestarle ${ }^{4}$, o simplemente el ambiente de Lima después de aquel viaje era asfixiante. Durante ocho años, de 1871 a 1879, Prada se retira a la hacienda familiar de Tutuma en Mala, provincia de Cañete "(...) Me dediqué por entero a la agricultura. Criaba gusanos de seda. Ocho años de mi vida pasaron en el campo en una labor activa y fecunda." ${ }^{5}$ Su pasión por la química industrial, experimentos en el laboratorio con el almidón de la yuca, por la nuevas aplicaciones agrícolas y las faenas campestres, se alternan con la escritura y la lectura (los poetas alemanes, los autores de los Siglos de Oro, Baudelaire, Menard, Omar Khayham, las obras de sus compañeros de bohemia y las revistas y libros que le llegaban directamente de Europa). Continúa reacio a las publicaciones, selecciona mucho su escritura, en El Correo del Perú su poesía oscila aún entre el romanticismo, de los lieder y las nuevas baladas indígenas sobre temas nativos, y las manifestaciones parnasianas.

Con la declaración de Guerra de Chile Manuel González Prada se enroló en el ejército, formando parte de la defensa del fuerte "El Pino" en la línea de Miraflores. Tras dos años de ocupación y de saqueo en Lima, en 1883 el General Manuel Iglesias firma el Tratado de Ancón, mediante el cual se cedían a Chile las provincias de Tacna y Arica durante diez años, y se establecían las condiciones de la devolución: el pago de diez millones de soles y la convocatoria de un Plebiscito sobre la elección de nacionalidad pasados aquellos años. El tema de las provincias cautivas atormentó la conciencia nacional, creando y cambiando vocaciones artísticas: en el caso de Prada la tremenda metamorfosis biográfica, el hombre de letras en su feliz exilio rural se transformó en el soldado del cruel combate, hizo de la prosa arma activa de revisión y reconstrucción de un Perú desesperado y patético. La poesía fue para siempre un hacer marginal.

La conferencia del Ateneo en 1886, el discurso del Palacio de la Exposición en 1887, sobre la tumba de Luis E. Márquez y los del Teatro Politeama y Olimpo en 1888, lo convierten en guía de una nueva generación científica, naturalista y de positivismo

\footnotetext{
4 Uno de sus lectores, el escritor José Domingo Cortés le pidió desde Valparaíso algunas composiciones poéticas y datos biográficos para una antología sobre poesía peruana, publicada en 1871 como Parnaso Peruano.

${ }^{5}$ Cfdo. por Willy Pinto, Manuel González Prada: profeta olvidado, Lima, Cibeles, 1987, págs. 31-33.
} 
revolucionario que agrupada en el Círcullo literario esperaba convertirse "en el partido radical de nuestra literatura." Este radicalismo literario comprometido con la función pública llevó a la fundación en 1891 del partido político Unión Nacional.

El antagonismo entre Ricardo Palma (1833-1919), líder del Club literario y la generación romántica anterior a la guerra, y Manuel González Prada más que formar parte del lógico relevo generacional polarizó la transición a la modernidad literaria, encendiendo pasiones enfrentadas que fuera de lo estético proponían una determinada idea de Patria o de Nación. El debate intelectual como debate político provocó una crítica sesgada que encumbró o condenó a su antojo, y que dejó importantes secuelas en la historiografía literaria del Perú.

Como explica Julio Ortega "Manuel González Prada inicia el discurso moderno de la denuncia de Lima. Lo hace desde su disidencia de clase, desde el antihispanismo y el anticlericalismo, y a partir de su fe positivista y anarquista. La indignación que comunica su denuncia es una nueva manera de hablar al país: una certidumbre moral enciende su alegato". ${ }^{6}$ Escojamos su discurso en el teatro Politeama donde el análisis de las causas de la derrota articuló todas las bases de su pensamiento: demolición del pasado, fatal herencia de un espíritu de servidumbre e ignorancia que se inicia como descendencia degeneradora de la nobleza española; regeneración del Perú a través de la ciencia positiva y la educación; proponer la realidad indígena como sustrato fundamental del Perú verdadero; y defensa de la juventud en la obra de reconstrucción y venganza "!Los viejos a la tumba, los jóvenes a la obra!"

Para forjar otro tipo de hombre, reeducar a los peruanos y orientar a la juventud, Prada propuso una "revolución desde arriba" realizada por un nuevo tipo de escritor, insumiso e indisciplinado con el Poder, con una obra de propaganda y ataque. Su diagnóstico de la literatura peruana fue "congestión de palabras, anemia de ideas", destacando la protección oficial y desproporcionada al libro hueco, el acaparamiento de los cargos públicos por las medianías literarias, y como vicios principales la freseología y la carencia de buenos estilistas.

Las críticas al romanticismo tradicionista de Ricardo Palma fueron constantes, la evocación de la colonia como germen histórico fundamental de las Tradiciones planteaba para Prada una postura ascaísta que protegía un nacionalismo regresivo causa del desastre peruano,

"Quien escribe hoy y desea vivir mañana, debe pertenecer al día, a la hora, al momento en que maneja su pluma. Si un autor sale de su tiempo, ha de ser para adivinar las cosas futuras, no para desenterrar ideas y palabras muertas.

Arcaísmo implica retroceso: a escritor arcaico, pensador retrógrado."

"Cultivamos una literatura de transición, vacilaciones, tanteos y luces crepusculares. De la poesía van desapareciendo las descoloridas imitaciones de Bécquer;

\footnotetext{
${ }^{6}$ Cultura y modernización en la Lima de 1900, Lima, CEDEP., 1986, pág. 71.
} 
pero en la prosa reina siempre la mala tradición, ese monstruo engendrado por las falsificaciones agridulces de la historia y la caricatura microscópica de la novela."7

El éxito y la fama de Ricardo Palma como escritor de tradiciones es anterior a la guerra, las cuatro primeras series (publicadas en 1872, 1874, 1875 y 1877) lo convierten en el gran creador de literatura historicista de su tiempo. La oligarquía limeña, que controlaba el gobierno, la universidad y la cultura, encontró en la tradición la fuerza legitimadora de su inmenso poder, la idealización de su ilustre pasado histórico desde la reconstrucción del mito de la Arcadia Colonial, el espíritu satírico criollo y un casticismo de sabor popular.

Desde la disidencia y la acusación la lectura palmista de Prada inaguró una larga historia de recepción sobre el significado real de las tradiciones que se extiende hasta hoy. También fue el antecedente más importante del debate sobre la literatura peruana que entre 1905 y 1938 contó con los nombres de José de la Riva Agüero, José Gálvez, Luis Alberto Sánchez, José Carlos Mariátegui y Martín Adán. ${ }^{8}$

El carácter literario de la obra de Prada fue más importante que su transcendencia política, el modernismo peruano encontró en su poesía los principios parnasianos y simbolistas, el acceso a una literatura cosmopolita que experimenta una serie de ritmos (el Rondeau francés, el ritmo helénico de acentuación silábica, el polirritmo sin rima como estructura métrica fundamental), ensaya la musicalidad del lenguaje e incluye abundante teoría sobre la nueva versificación. Minúsculas (1901) y Exóticas (1911) son los textos fundadores de esta pureza y superioridad estéticas, aunque su obra poética incluirá también crítica social, política, religiosa o filosófica en estricto paralelismo con su prosa, el fuerte sentido utilitario y pragmático que ésta poseía para Prada decidió la publicación excluyente de aquellos poemarios. ${ }^{9}$

Sin embargo la voz poética de modernismo estuvo representada en soledad por el genio y la figura de José Santos Chocano (1879-1884). Curiosamente el mismo González Prada ayudó a su encumbramiento, primero formando parte del jurado del Ateneo de Lima que en un concurso de poesías sobre un episodio de la Guerra del Pacífico (la hazaña del Morro en 1881, la resistencia heróica del coronel Francisco Bolognesi en Arica) premió La Epopeya del Morro (1899); después, redactando un prólogo para sus Obras Completas (1901) en el

\footnotetext{
${ }^{7}$ El primer fragmento pertenece a la conferencia del Ateneo, el segundo al discurso en el teatro Politeama, textos publicados por su autor en su primer libro de ensayos Páginas libres (Paris, 1894). Nosotros hemos consultado la edición de Ayacucho (Caracas, 1976, págs. 15 y 27 respectivamente). Decepcionado por la imposibilidad de llevar a cabo sus reformas Prada se marchó a Europa, las fechas de este nuevo exilio: 18911898.

${ }^{8}$ Miguel Angel Rodríguez Rea en La literatura peruana en debate, realiza un interesante y completo análisis de estos estudios. Los textos fueron: José de la Riva Agüero, Carácter de la literatura del Perú independiente (1905). José Gálvez, Posibilidad de una genuina literatura nacional, (1915). Luis Alberto Sánchez, Nosotros: ensayo sobre una literatura nacional (1920). José Carlos Mariátegui, 7Ensayos..., (1928). Martín Adán, De lo Barroco en el Perú, (1938).

9 También publicó anónimamente el poemario anticlerical Presbiterianas. Alfredo González Prada y Luis Alberto Sánchez editaron toda esta poesía que salvo raros ejemplos quedó en manuscritos privados, los volúmenes fueron numerosos: Trozos de vida, Baladas peruanas, Grafitos, Libertarias, Adoración, Letrilllas, Baladas y Poemas desconocidos.
} 
cual le otorga el título de "Poeta nacional del Perú". Con la publicación en 1906 de Alma América: poemasi ndo-españoles Chocano rechaza toda su obra anterior, fundamentalmente aquella poesía épica de nacionalismo exaltado en La Epopeya del Morro, que en Iras Santas (1895) planteaba obsesivamente la misión social del poeta-guerrero en su compromiso con el pueblo contra el tirano.

El modernismo de Chocano se convirtió en el estilo nacional, continuación ideológica de Palma en una modernidad sin ruptura a través de un neocolonialismo que mantiene los ídolos del ayer, la fe católica y la herencia latina de una raza. Su discurso americanista fuertemente estructurado en "lo limeño" recupera todo un mundo de símbolos saturados de pasado, con sus personajes, su arquitectura y sus tópicos: La Tapada, Alameda Colonial, El tesoro de los incas, la Perricholi, etc.

Con esta poesía de la raza hispanoamericana Chocano esperaba arrebatarle su cetro a Rubén Darío, no lo consiguió pero su algarada impidió escuchar otras voces modernistas como la búsqueda poética de Prada o la palabra símbolica de José María Eguren. Ausente del Perú desde 1905 hasta 1921 su Coronación Nacional en 1922, el presidente Leguía en manos de Clemente Palma colocó los laureles de oro sobre su frente, convertirá este modernismo en estética de estado y término fundamental de la oposición literaria vanguardista.

La generación novecentista rendirá un homenaje ininterrumpido a su "cantor de América", seguidores de Rodó formalizaron el pensamiento tradicional en su concepto y diseño de la realidad peruana. Miembros de este primera generación modernista fueron Francisco García Calderón, su hermano Ventura, José de la Riva Agüero y José Gálvez, entre otros, estudiantes de la Universidad de San Marcos durante su juventud se formaron en una belle époque de principios de siglo que desapareció con la revolución mexicana, la Primera Guerra Mundial y la revolución soviética, cuando América Latina entra en un periodo de trastornos sociales y económicos.

Generación de prosistas, pensadores graves e intelectualizados, publican sus primeros libros antes de 1914, "mateniendo durante cierto tiempo una posición dominante en la cultura peruana y los valores que representaban, aunque no correspondiesen a la evolución del país -o precisamente por eso- se convirtieron en valores oficiales." 10 Casi todos se declararon adversarios de Leguía y pasaron en el destierro el oncenio de su último gobierno (1919-193), comienzo real de la modernidad vanguardista. Quedó como representante José de la Riva Agüero, su miembro más radical y conservador, cuya temprana indiferencia y hostilidad al modernismo lo diferencia del resto de su grupo.

Como explica Abraham Arias-Larreta hacia 1915 comienza a tambalearse esta bastilla literaria instaurada en Lima desde la Colonia, Ricardo Palma, Chocano o José de la Riva Agüero centralizaron la dirección y el prestigio cultural peruano. "De sus cenáculos salían las directivas y las normas, los rumbos y las consagraciones literarias. (...) de pronto, con

10 Cfdo. Luis Loayza, "Inactualidad del Novecientos", Sobre el Novecientos, Lima, Mosca Azul Editores, 1990, pág. 12. 
un empuje inesperado, insurgen las provincias. Y la región -como lo registra Alberto Uretacobra un valor desconocido y hasta una beligerancia inusitada en la literatura peruana."11

Abraham Valdelomar (Ica 1888-Ayacucho 1919) fue uno de los primeros escritores de provincia que revoluciona el orden cultural establecido por la intelectualidad limeña. Su revista Colónida (1916), que con un modernismo snob y aristocratizante mantuvo el ambiguo equilibrio entre la insurrección y el respeto a los novecentista, alentó la formación de otro grupos y fue un ejemplo a seguir. Los escritores inmigrados (la lista es interminable: Ernesto More, César Vallejo, Jorge Basadre, Alberto Hidalgo, Percy Gibson, Valcárcel, Haya de la Torre, Alberto Guillén...) rompen el monopolio civilista sobra la vida cultural, asumiendo en numerosas ocasiones posiciones críticas que reconocen como suyo el pensamiento progresista de González Prada, vinculándose a los movimientos pupulares a través de la Reforma Universitaria de 1918.

Para entonces la casa de los González Prada se había convertido en centro fundamental de las nuevas heterodoxias literarias, la influencia ejercida sobre las jóvenes generaciones se intensificó a través de su hijo Alfrefo miembro de Colónida. En 1916 con una serie de entrevistas realizadas por Félix del Valle, Valdelomar y Mariátegui, declaró la superioridad sin precedentes de esta misma juventud, "¿Qué opina usted de la generación actual de escritores? Que es superior a todas las precedentes. (...) En general, hoy existe más cultura literaria." 12

Esta defensa lo fue también de sus propios lectores, su obra los había ido formando lentamente en el tiempo, enfrentándoles con el ejercicio crítico de una palabra cuya independencia estética o indignación moral obligaban a una nueva forma de compromiso con la escritura. José Carlos Mariátegui fue uno sus discípulos más interesantes, su adolescencia colónida marcada por la colaboración estrecha con Abraham Valdelomar y su vocación de cronista político ${ }^{13}$ cimentaron una amistad comenzada en 1909.

La trayectoria intelectual de González Prada fue seguida por gran parte de la joven intelectualidad revolucionaria de su época, así como de la época contemporánea: la toma de conciencia política pasaba en su fase inicial por la literatura, cuyo ejercicio se entendía como un proceso imprescindible de esclarecimiento ideológico y orientación de criterios. En 1918 muere Manuel González Prada, al año siguiente Mariátegui inicia un exilio europeo que le mantendrá alejado hasta 1923. En septiembre de 1926 se publica el primer número de la revista Amauta, en su "Presentación" encontramos expresado el proyecto ambicioso de una vanguardia que guarda en su interior una voz conocida, una deuda inmensa

\footnotetext{
11 "Realidad lírica peruana", Revista Iberoamericana, Pittsburg noviembre de 1941, págs. 55-56.

12 Cfdo. por Willy Pinto, op. cit., pág. 45.

${ }^{13}$ La colaboración con Valdelomar incluye: la publicación de tres sonetos de Mariátegui en Colónida, núm. 3; el trabajo para la misma revista ilustrada Lulu; y el trabajo conjunto en el drama en verso LaMariscala. El periodismo político le llevó a trabajar en ElTiempo, fundar la revista NuestraEpoca (1918) y el diario LaRazón (1919). En este último diario se convierte en portavoz de los obreros, estudiantes y el pueblo al apoyar las huelgas, los paros y las manifestaciones. El presidente Leguía le "beca" para una estancia en el extranjero.
} 
Esta revista, en el campo intelectual, no representa un grupo. Representa más bien, un movimiento, un espíritu. En el Perú, se siente desde hace algún tiempo una corriente, cada día más vigorosa y definida, de renovación. A los fautores de esta renovación se les llama vanguardistas, socialistas, revolucionarios, etc. (...) Por encima de lo que los diferencia, todos estos espíritus ponen lo que los aproxima y mancomuna: su voluntad de crear un Perú nuevo dentro del mundo nuevo.

(...) Amauta cribará a los hombres de la vanguardia militantes y simpatizanteshasta separar la paja del grano. (...) al Perú le nace en este momento una revista histórica." 14

14 José Carlos Mariátegui, Obras, t. II, La Habana, Casa de Las Américas, 1982, págs. 238-239. 
